\title{
Accessing genitourinary medicine clinics: does it matter where you live?
}

\author{
Beth Stuart, Andrew Hinde
}

School of Social Sciences and Southampton Statistical Sciences Research Institute, University of Southampton, Southampton, UK

\section{Correspondence to} Dr Beth Stuart, Division of Social Statistics, University of Southampton, Building 58, University Road, Southampton S017 1BJ, UK;

bls1@soton.ac.uk

Received 6 April 2010 Accepted 21 October 2010 Published Online First 13 April 2011

\section{Abstract}

Objectives To determine whether genitourinary medicine (GUM) clinics in England are located conveniently for potential users and to assess whether there are any regional variations in accessibility.

Methods A surface model was created

in ArcGIS to estimate driving times to the nearest GUM clinic and to identify the proportion of the population living more than 30 minutes drive from their nearest clinic. Results Overall, $3.0 \%$ of the population live further than 30 minutes from their nearest clinic. However, this average figure disguises considerable regional variation. While access in London and the South East was excellent, with less than $1 \%$ of the population living more than 30 minutes from the nearest clinic, in the South West and the East of England, these percentages rose to $7.7 \%$ and $9.2 \%$, respectively.

Conclusions In some regions of England it is important to consider the physical barriers to clinic access, as inability or unwillingness to undertake a long journey to a GUM clinic may increase the workload in other clinical settings.

\section{Introduction}

In the 2004 'Choosing Health' White Paper, the Government made improving sexual health a priority and promised that "by 2008 patients referred to GUM clinics will be able to have an appointment within 48 hours". ${ }^{1}$ At the end of 2008 , $96 \%$ of primary care trust (PCTs) had met the 48-hour target. ${ }^{2}$ Being provided with timely access to genitourinary medicine (GUM) services means that individuals with sexually transmitted infections (STIs) are diagnosed and treated quickly, thereby limiting the risk of their passing the infection on to a sexual partner.

However, the availability of appointments is only one aspect of accessibility. The National Institute for Health and Clinical Excellence (NICE) defined accessibility as including whether and how easily people are able to reach key services such as health

\section{Key message points}

Access to genitourinary medicine (GUM) services in England is good, with only $3 \%$ of the population living more than 30 minutes from their nearest clinic.

There are considerable regional variations, with accessibility in the South West and East of England being much worse than the national average.

In areas where access has been indentified as being problematic, the impact on non-GUM settings should be considered.

care. $^{3}$ Our study examined this physical aspect of accessibility, that is, how long it takes individuals to travel to their nearest GUM clinic. A measure of travel time to the nearest clinic is likely to reflect peoples' real experiences of trying to access GUM services. Using this measure, calculated using a geographic information system (GIS), this study examined the accessibility of clinics in England to determine whether clinics are conveniently located for the majority of the population and to explore whether there are any detectable regional variations.

\section{Methods}

A list of all clinics in England was obtained from the Department of Health Genitourinary Medicine Access Monthly Monitoring data on appointment waiting times $^{4}$ and was geo-referenced based on postcode. Northing and Easting grid references were obtained for each clinic using the 2000 All Fields Postcode Directory, available from UK Borders. In ArcGIS these were overlaid onto an administrative map of England that showed Lower Super Output Areas (LSOAs) from the 2001 Census and Government Office Regions (GORs) and also included information about the population structure at both geographical levels.

Measuring the travel time for an individual patient from their home to a clinic is relatively straightforward. Trip-planning software, such as www.multimap.com and Google Maps, provide good pointto-point estimates of journey time. Using these programmes to provide a general 
picture of accessibility across a large geographical area is problematic. Anyone living in the region could be a potential patient but it would be impossible to use every individual address as a starting point. Even a sample of starting points would require an unfeasibly large number of calculations in order to ensure that the results were representative.

The use of a GIS programme considerably simplifies the calculations. The area under consideration is divided into a grid of $100 \mathrm{~m}^{2}$ and the programme creates a sample of starting points evenly distributed across the region at very small intervals. It is then assumed that from these starting points, potential patients travel from square to square, along the UK road network, until they reach the nearest clinic. The path chosen for the journey is the one that minimises travel time. ${ }^{5}$

The representation of the road network was obtained from the Ordnance Survey Meridian 2 Collection (1:50 000 scale) and included four classifications of road types: motorway, A-road, B-road and minor road. The calculation of journey time required assumptions about how quickly traffic moves along each road type. The speeds assigned to the roads in the model, shown in Table 1, were based on the average road speeds reported by the Department of Transport ${ }^{6}$ and upon empirical work to verify travel times to health services done by Haynes et al. ${ }^{7}$

Road speeds in urban areas were assumed to be half of those in rural areas to take into account the time-cost of traffic congestion in urban areas. The designation of an area as urban or rural was based on classifications made by the Rural and Urban Area Classification Project. ${ }^{8}$

There is no established duration that is considered 'too long' to expect individuals to travel. A number of studies of the accessibility of National Health Service (NHS) have used a travel time of more than 30 minutes $^{9-11}$ and this paper will follow that convention. It is recognised that some individuals will choose to access their nearest clinic while others will be willing to undertake a long journey to access services in a place where they feel anonymous. This model is therefore one of potential, rather than actual, accessibility.

\section{Results}

Overall, it is estimated that 3\% of the population of England lives more than 30 minutes from the nearest clinic. This suggests that for the country as a whole, remoteness from GUM services does not represent a significant problem. The geographical distribution of journey times is shown in Figure 1, with the areas shaded in the light grey representing the areas from which the journey to the nearest clinic takes less than 30 minutes and the dark grey representing a journey time of more than 30 minutes. Only a very small proportion of the population had extremely long estimated journey times. The longest journey time calculated was over 3 hours but only $0.08 \%$ of the population had a journey time of more than 1 hour.

Although accessibility for the whole country was generally good, there was considerable regional variation, as shown in Table 2. Access was excellent in London and the South East. No LSOAs in London and only 35 in the South East were located more than 30 minutes from a clinic. Access was also very good in the North West and East Midlands, with only $1.3 \%$ and $2.1 \%$ of the population located more than 30 minutes from a clinic. The South West and East of England had the poorest levels of accessibility with $7.7 \%$ and $9.2 \%$ of the population, respectively, unable to reach a clinic within 30 minutes.

The age distribution of these regions varies. For example, the South West and East of England GORs have an older age structure than areas with better

Table 1 Travel speeds assigned to roads in the model employed in the study

\begin{tabular}{lll}
\hline Road type & Rural speed (mph) & Urban speed (mph) \\
\hline Motorway & 65 & 33 \\
A-road & 45 & 23 \\
B-road & 30 & 15 \\
Minor road & 20 & 10 \\
Walking & 4 & 4 \\
\hline
\end{tabular}

mph, miles per hour.

Table 2 Proportion of the population living more than 30 minutes driving time from the nearest genitourinary medicine clinic

\begin{tabular}{lll}
\hline & $\begin{array}{l}\text { Proportion of the total population living } \\
\text { more than } 30 \text { minutes drive from the } \\
\text { nearest clinic (\%) }\end{array}$ & $\begin{array}{l}\text { Proportion of the total population aged } \\
16-29 \text { years living more than } 30 \text { minutes } \\
\text { drive from the nearest clinic (\%) }\end{array}$ \\
\hline East Midlands & 2.1 & 1.8 \\
East of England & 9.2 & 7.8 \\
North East & 3.8 & 2.8 \\
North West & 1.3 & 1.0 \\
London & 0.0 & 0.0 \\
South East & 0.6 & 0.6 \\
South West & 7.7 & 6.3 \\
West Midlands & 2.7 & 2.0 \\
Yorkshire and Humberside & 2.7 & 1.9 \\
\hline
\end{tabular}




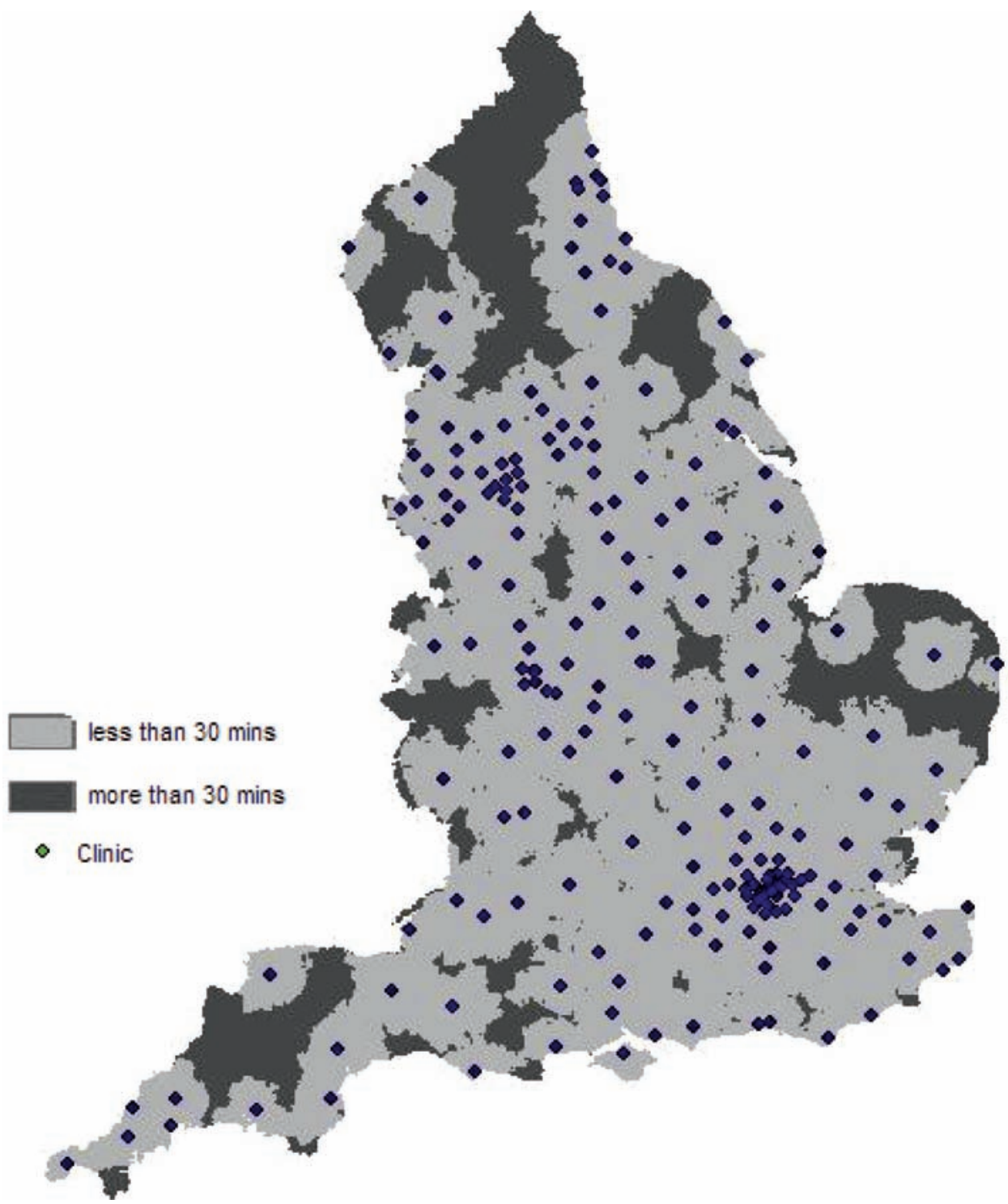

Figure 1 Map of England showing the location of genitourinary medicine clinics and the geographical distribution of journey times to these clinics

accessibility such as London and the South East. ${ }^{12}$ According to the Health Protection Agency (HPA), young people are more likely than any other age group to be diagnosed with an STI. ${ }^{13}$ Thus older individuals may be less likely to require sexual health services and the poorer levels of accessibility noted above may not be a cause for concern. We therefore considered the proportion of the population aged 16-29 years located more than 30 minutes from a clinic.

The pattern for the population aged 16-29 years was similar to that observed for the population as a whole. Overall, 2.1\% of 16-29-year-olds were unable to reach a clinic within 30 minutes. Access in London, the South East and the North West was excellent with over 99\% of young people able to access a clinic within 30 minutes. However, as shown in Table 2, access in the South West and East of England remained problematic, with $6.3 \%$ and $7.8 \%$ of $16-29$-year-olds, respectively, located more than 30 minutes from the nearest clinic. Although these figures represented a reduction on those for the whole population, they still showed that a substantial proportion of young people in these areas would be unable to access a GUM clinic within 30 minutes.

\section{Discussion}

This paper demonstrates an interesting regional difference in the physical accessibility of GUM services. Almost 100\% of the population in London and the South East have an estimated journey time of less than 30 minutes to reach their nearest clinic, while access in the South West and East of England regions is estimated to be far more problematic. So far, initiatives to make GUM clinics more accessible have concentrated on ensuring that an appointment can be obtained within 48 hours. However, this study has highlighted that in more remote areas it may be difficult for potential patients to attend a clinic due to the long travel time to the nearest site. 
Although clinic access in the South West and East of England is more problematic, in 2008/2009 the data from the HPA showed these Strategic Health Authorities had lower rates of chlamydia, gonorrhoea, genital warts and genital herpes than the average for the whole of England. ${ }^{14}$ We could therefore be cautiously optimistic that the areas with greater accessibility issues are also those with lower than average STI rates and hence less demand for sexual health services. However, the data only reflect diagnoses made at GUM clinics and therefore these lower rates may not indicate a lower burden of disease in the population of these areas. Regional differences could also be due to differences in testing patterns or, as highlighted by our calculations, differences in ability to access GUM clinics. For chlamydia diagnoses, data are available for diagnoses made in non-GUM settings, but only for the 16-25year age group. ${ }^{15}$ Taking all settings into account, these data also showed lower rates in the South West and East of England than the national average. However, the non-GUM setting data are based only on one age group and, even then, the rates of chlamydia are lower than in other regions but not necessarily low in absolute terms: 290.9 per 100000 population in the East of England and 308.5 per 100000 population in the South West. ${ }^{15}$ There is still a substantial burden of STI, and thus need for access to GUM services, even in the areas with the lowest rates.

Of course, sexual health services in the UK are not only provided in the GUM clinic setting. For example, the South West HPA observed that within their region a large proportion of chlamydia diagnoses are being made by general practitioners (GPs) or in clinical settings other than GUM clinics. They note that "increasing use of postal kits and provision of enhanced sexual health services in primary care reflects the regional need to reach rural populations with little access to other services" ${ }^{16}$ A survey by the HPA in 2008 examined the provision of Level 2 sexual health services (i.e. provision of testing, diagnosis and treatment) in non-GUM settings and found that $92 \%$ of PCTs in the South West provided these services, usually at enhanced GP practices and community sexual health clinics. In contrast, only $60 \%$ of PCTs in the East of England provide such services, which is perhaps surprising given that this is the area with the highest proportion of the population living more than 30 minutes from the nearest clinic. ${ }^{17}$

These Level 2 services, including enhanced GP practices, community and satellite clinics and outreach centres, are an excellent initiative and this model might be expanded further in areas where clinic accessibility is an issue. However, the 2008 review undertaken by the Medical Foundation for Aids and Sexual Health highlighted that the quality of local services can be variable. ${ }^{18}$ Moreover, a pilot project by Plymouth Hospital GUM clinic to run additional satellite services found that "only the most basic GU medicine service could be provided efficiently in the community. Patients with more complex problems required referral to the main clinic for optimal management". ${ }^{19}$

While the quality of many non-GUM services can be excellent, if people are seeking treatment in settings other than GUM clinics then an important investment may be in ensuring that health practitioners across all these settings have received appropriate training to deal with all aspects of sexual health and that they have the time and resources to devote to its detection and treatment. For example, a survey of GPs and nurses in Dyfed Powys, a health authority in rural southwest Wales, found that the majority were in favour of further training and support to help them manage the treatment of chlamydia infection properly. ${ }^{20}$ Following the 2008 MedFASH report, new guidelines were issued in 2010 and it will be interesting to see what the impact of these will be..$^{21}$

Postal kits, such as those made available through the National Chlamydia Screening Programme (NCSP), could also be an excellent way of reaching those in more remote locations as well as those individuals who cannot or do not wish to attend an appointment. The NCSP is currently limited to those aged under 25 years and tests only for chlamydia. There are Internet-based services available that allow individuals to purchase a kit to test themselves for a range of STIs, but unlike NHS-based services these are not free and a study by Owens et al. found the testing sites were often difficult to contact with questions and that the home testing kits had poor accuracy, though mail-in kits were better. ${ }^{22}$

This study does have a number of limitations. The calculation of travel time is a measure of estimated drive time. A car's speed, and thus the time taken to complete a journey, will vary by time of day, by region and even by driver. The speeds assigned to the roads in calculating the journey times are therefore only estimates based on average speeds. The journey time also does not take into account other activities which affect the overall travel time, such as the time spent trying to park at the clinic. Nor does it represent the time taken to get to a clinic by individuals who do not have access to a car and who therefore rely on public transport. Therefore these calculations will only be an approximation of the time taken for an individual to get to the clinic and may substantially understate the true time taken by some users. It also does not take into account other barriers to access, such as the cost of travelling to the clinic or the impact of taking time off work to attend an appointment.

Comprehensive public transport data were not available for this study and it is unclear what proportion of GUM service users rely on public transport. However, several studies have suggested that it may be a substantial number, particularly among young people. A study of five clinics in the West Midlands found that $66 \%$ of patients used public transport or walked, ${ }^{23}$ while a study of service users in Southampton noted that $60 \%$ travelled to the clinic by a method other than driving, rising to $91 \%$ of patients aged under 16 years and $75 \%$ of patients aged $16-17$ years. ${ }^{24}$ For those using public 
transport, it is likely that the times calculated in this paper represent a significant underestimate, though it is impossible to say by how much.

It may be that the perception of remoteness varies by area. People living in especially rural locations may be used to travelling long distances to access all kinds of services and therefore the prospect of a 40- or 50-minute journey to reach the GUM clinic might not seem daunting to them. For example, this study has highlighted that access in the area surrounding the Plymouth clinic may be problematic, with many users having to travel more than 30 minutes. However, if people living in the areas surrounding Plymouth are used to having to travel more than 30 minutes to get petrol for their cars or to visit their nearest supermarket, then the time taken to get to the clinic might not be off-putting.

Not many studies have examined clinic accessibility within a UK context. One which did examined the accessibility of a clinic in Plymouth. It found that $20 \%$ of users reported travelling more than 30 minutes to reach the clinic and only $69 \%$ reported that they found the clinic location, Derriford Hospital, "convenient". ${ }^{25}$ This suggests that longer travel times might not be relative, and that the time taken to travel to the clinic might be off-putting to some potential patients. In addition, the potentially long journey times may impact the ability to reach key groups. In the Southampton study, just $2 \%$ of young people stated that they were prepared to travel more than 30 minutes to access sexual health services. ${ }^{24}$

It is vitally important that individuals have access to appointments at GUM clinics as quickly as possible. This study in no way wishes to detract from the substantial efforts that have been and continue to be made to ensure that the 48-hour waiting time is met across the country, nor from the efforts made at the local level to provide high-quality services in a non-GUM clinic setting. Patients have a number of options when seeking sexual health screening and treatment and it is likely that the proximity of a clinic to an individual's home is an important consideration in deciding whether or not to attend a GUM clinic. It therefore is important to consider geographical accessibility when planning how STI services will be delivered at the local level in order to ensure that everyone has access to high-quality sexual health services.

\section{Competing interests None.}

Provenance and peer review Not commissioned; externally peer reviewed.

\section{References}

1 Department of Health. Choosing Health: Making Healthy Choices Easier, 15. 2004. http://www.dh.gov.uk/en/ Publicationsandstatistics/Publications/PublicationsPolicyAnd Guidance/DH_4094550 [accessed 28 March 2008].

2 Care Quality Commission. NHS Performance Ratings 2008/2009. London, UK: CQC, 2009.

3 National Institute for Health and Clinical Excellence. Accessibility Planning and the NHS: Improving Patient Access to Health Services. 2006. http://www.nice.org.uk/aboutnice/ whoweare/aboutthehda/hdapublications/accessibility_planning and_the_nhs_improving_patient_access_to_health_services.jsp [accessed 26 March 2008].

4 Department of Health. 48 Hour Genitourinary Medicine Access Monthly Monitoring. 2009. http://www.dh.gov.uk/en/ Publicationsandstatistics/Statistics/Performancedataandstatistics/ SexualHealth/index.htm [accessed 19 March 2009].

5 Martin D, Wrigley H, Burnett S, et al. Increasing the sophistication of access measurement in a rural healthcare study. Health Place 2002;8:3-13.

6 Department of Transport. Traffic Speeds on English Trunk Roads: 2003, 2004. http://www.dft.gov.uk/pgr/statistics/ datatablespublications/roadstraffic/speedscongestion/trunkroads/ trafficspeedsonenglishtrunkr5364 [accessed 15 August 2007].

7 Haynes R, Jones AP, Sauerzapf V, et al. Validation of travel times to hospital estimated by GIS. Int J Health Geogr 2006;5:40.

8 Office for National Statistics. Rural and Urban Area Classification 2004: An Introductory Guide. 2005. http:// www.ons.gov.uk/about-statistics/geography/products/areaclassifications/rural-urban-definition-and-la-classification/ruralurban-definition/index.html [accessed 21 March 2011].

9 Propper C, Burgess S, Green K. Does Competition Between Hospitals Improve the Quality of Care?: Hospital Death Rates and the NHS Internal Market. CMPO Working Paper 00/27, 2000.

10 North Bristol NHS Trust. North Bristol and South Gloucestershire Hospital Service Configuration Appraisal. 2004. http://www.avon.nhs.uk/bhsp/documents/2004_ Reports/041101_BHSP_North_Bristol_Trust_Transport_ Appraisal_Nov0 4 .pdf [accessed 21 March 2011].

11 Wood DJ, Gatrell AC. Equity of Geographical Access to Inpatient Hospice Care Within North West England: A Geographical Information Systems (GIS) Approach. 2002. http://www.nwph.net/ nwpho/Publications/inpatientgis.doc [accessed 11 October 2007].

12 Office for National Statistics. 2008-Based Subnational Population Projections for England. 2010. http://www.statistics. gov.uk/pdfdir/pproj0510.pdf [accessed 16 August 2010].

13 Health Protection Agency. Sexually Transmitted Infections and Young People in the United Kingdom: 2008 Report. 2008. http:// www.hpa.org.uk/web/HPAwebFile/HPAweb_C/1216022461534 [accessed 16 August 2010].

14 Health Protection Agency. Number and Rates of Selected STI Diagnoses Made at Genitourinary Medicine Clinics by Gender and Age Group in the UK, England and English SHAs: 2005-2009. 2010. http://www.hpa.org.uk/web/HPAweb\&HPAwebStandard/ HPAweb_C/1203348026613\#3._STI_Epidemiology_in_2009_ (England) [accessed 20 September 2010].

15 Health Protection Agency. Number and Rates of New Diagnoses of Genital Chlamydia Diagnoses Made in Any Setting, by Gender and Age-group in the UK, England and English SHAs: 2008-2009. 2010. http://www.hpa.org.uk/web/ PAweb\&HPAwebStandard/HPAweb_C/1203348026613\#3. STI_Epidemiology_in_2009_(England) [accessed 20 September 2010].

16 Health Protection Agency South West. Chlamydia screening by venue in the South West. South West Sexual Health Task Group Quarterly Bulletin 2007;4:2.

17 Health Protection Agency. Summary of Level 2 Sexual Health Services in England. 2008. http://www.swagnet.nhs.uk/PCT\%20 Survey\%20of\%20level\%202\%20SH\%20services\%20agg_ v2\%201.pdf [accessed 20 September 2010].

18 Medical Foundation for AIDS \& Sexual Health. Progress and Priorities - Working Together for High Quality Sexual Health: 
Review of the National Strategy for Sexual Health and HIV. 2008. http://www.medfash.org.uk/publications/documents/ Progress_and_priorities_working_together_for_high $\% 20$ quality_sexual_health_FULL_REPORT.pdf [accessed 20 September 2010].

19 Challenor R, Pinsent S, Baker D. Improving access to genitourinary medicine by satellite clinics: an evaluation of the use of pump-priming funding. Int J STD AIDS 2005;16:51.

20 Griffiths C, Cuddigan A. Clinical management of chlamydia in general practices: a survey of reported practice. J Fam Plann Reprod Health Care 2002;28:149-152.

21 Medical Foundation for AIDS \& Sexual Health. Standards for the Management of Sexually Transmitted Infections. 2010. http:// www.medfash.org.uk/Projects/BASHH\%20standards/Final\%20
pdfs/Standards_for_the_management_of_STIs.pdf [accessed 20 September 2010].

22 Owens S, Arora N, Quinn N, et al. Utilising the internet to test for sexually transmitted infections: results of a survey and accuracy testing. Sex Transm Infect 2010;86:112-116.

23 Hope V, MacArthur C. Accessibility of genitourinary medicine clinics. Genitourin Med 1996;72:52-55.

24 Stone N, Ingham R. Exploring the Variations in the Characteristics of Young People's Services in Southampton. Southampton, UK: Centre for Sexual Health Research, 2007.

25 Malu M, Challenor R, Rodgers C. An audit to evaluate the accessibility, cost, impact on work place absence and convenience of attending genitourinary medicine clinics in London and Plymouth. Int J STD AIDS 2003;14:55-57. 